\title{
Sorption Model and Kinetic Assessment of Ultramarine Blue Removal using Modified Cassava Peels Biomass
}

\author{
Hilary I. Owamah ${ }^{1 *}$, Osadolor C.Izinyon ${ }^{2}$ and Augustine K. Asiagwu ${ }^{3}$ \\ ${ }^{1}$ Civil Engineering Department, Landmark University, Omu-Aran, Kwara State, P.M.B.1001, Nigeria \\ ${ }^{2}$ Civil Engineering Department, University of Benin, Benin, Edo State, Nigeria \\ ${ }^{3}$ Chemistry Department, Delta State University, Abraka, Nigeria
}

\begin{abstract}
The efficiency of modified cassava peels biomass for the removal of ultramarine blue (UB), has been thoroughly investigated in this study. The effect of changing absorbent concentration, UB concentration, contact time and $\mathrm{pH}$ had been studied. Maximum absorption occurred at $\mathrm{pH}$ of 10 . There was a general increase in UB absorption with increase in absorbent concentration, UB concentration, time and temperature, respectively. The pseudo second order equation with $\mathrm{R}^{2}$ of 0.952 , provided a better description of the adsorption process than the first order, showing that adsorption occurred mainly due to intra-particle diffusion. The Freundlich and Langmuir isotherms were applied to the equilibrium data. The adsorption capacity $\left(Q_{m}\right)$ obtained from the Langmuir isotherm was $0.952(\mathrm{mg} / \mathrm{g})$. The separation factor $\mathrm{RL}$ was obtained as 0.663 is less than unity, indicating that modified cassava peels biomass is a good absorbent for UB. The assessed thermodynamic parameters showed that the adsorption of UB on modified cassava peels biomass was endothermic.
\end{abstract}

Keywords: Adsorption kinetics; Dye removal; Absorption isotherms and models

\section{Introduction}

Water pollution due to the discharge of dyeing industry effluent is a major concern these days. Many techniques like electrochemical coagulation, reverse osmosis, nano-filtration, adsorption using activated materials etc., are used for the removal of dye from waste water. Adsorption was proved an efficient and economical process to treat dyeing industry effluent. In recent years, many natural waste materials have been investigated to assess their suitability as an adsorbent. Exploration of a good low cost adsorbent may contribute to the sustainability of the environment and also offer promising benefits for commercial purposes in future. Recently some agricultural wastes and forestry products have been developed as adsorbents. Activated carbon prepared from different materials like agricultural wastes [1,2], and oil palmwaste [3], babool seed [4], eucalyptus bark [5], pine saw dust [6], pistachio shells [7,8],also investigated the mechanistic study of dye adsorption onto a novel non-conventional low-cost adsorbent. The Dyes production industries and many other industries which utilize dyes and pigments are increasing globally everyday as far as technology advancement is concerned. Presently, it was estimated that about 10,000 of different commercial dyes and pigments exist and over $7 \times 10^{5}$ tones are produced annually worldwide [9]. These industries include textile, paper, plastic, food cosmetic etc, in which textile rank first and their wastes being discharged consist majorly of these dyes and pigments. Consequently, this constitute environmental hazard due to the fact that many of these dyes and pigments are difficult to degrade. They are generally stable to light, oxidizing agents and are resistant to aerobic digestion [10]. Hence, contaminations due to dyes are not only environmentally hazardous but are also of severe public health concern because of their persistence in nature and non- biodegradability.

However, the removal of dyes from the wastes discharged by the afore-mentioned industries, especially textile industries now call for urgent attention in order to safeguard our environment and public health. In this regard, a number of conventional methods as mentioned before are available for the removal of dyes from industrial effluents, including ion exchange, adsorption, membrane technology and coagulation. But in all, adsorption, which is a process that occurs when a gas or liquid solute accumulate on the surface of a solid or a liquid (adsorbent), forming a film of molecules or atoms (the adsorbate), has been one of the effective methods adopted so far. The adsorption has an edge over the other methods due to its sludge free clean operation and the possibility of complete dyes removal, even from the diluted solution.

Meanwhile, in adopting adsorption method in the removal of dyes, activated carbon (powdered or granular) has been one of the most widely used adsorbents. This is due to the fact that it has excellent adsorption efficiency for organic compound, through its use is limited in the industries of developing countries due to its high cost. Several studies have shown that numerous low cost material have been successfully applied in the removal of dyes from aqueous solution, some of which are coal, fly ash, wood silica, agricultural waste etc. however, only few of them could be employed effectively to remove dyes from the waste stream.

In this study, the potential of modified cassava peels in the removal of ultramarine blue dye from aqueous solution has been investigated. It is a low cost agro-industrial waste that is common in the southern part of Nigeria. Experimental parameters affecting the adsorption process such as $\mathrm{pH}$, concentration, adsorbent dosage, contact time and temperature were studied. The equilibrium adsorption data were fitted into Langmuir and Freundlich isotherms, pseudo-first order and pseudo-second order kinetic equations were also considered. Thermodynamic parameters were estimated in order to study the nature of the system.

\section{Materials and Methods}

\section{A Sample collection and preparation of the adsorbent}

About $1.5 \mathrm{~kg}$ of cassava (manihot esculenta cranz) peels were

*Corresponding author: Owamah HI, Civil Engineering Department, Landmark University, Omu-Aran, Kwara State, P.M.B.1001, Nigeria, Tel:+2340835705814, E-mail: dahilla222@yahoo.com

Received July 02, 2012; Accepted October 03, 2012; Published October 10 2012

Citation: Owamah HI, Izinyon OC, Asiagwu AK (2012) Sorption Model and Kinetic Assessment of Ultramarine Blue Removal using Modified Cassava Peels Biomass. J Civil Environ Eng 2:122. doi:10.4172/2165-784X.1000122

Copyright: (c) 2012 Owamah HI, et al. This is an open-access article distributed under the terms of the Creative Commons Attribution License, which permits unrestricted use, distribution, and reproduction in any medium, provided the original author and source are credited. 
collected from a cassava mill in Ibusa in Oshimili North Local government Area of Delta State. These were extensively washed with tap water to remove soil and dust, sprayed with distilled water and then sun-dried for five days. The dried cassava peels were burnt in the absence of free excess air in order to get the charcoal. The charcoal obtained was further ground and sieved using $450 \mathrm{um}$ sieve. The sieved adsorbent obtained was preserved in a plastic container for further studies.

\section{Preparation of dye solution}

The dye (ultramarine blue) used in this study was obtained from a commercial market without further purification. The dye stock solution was prepared by dissolving accurately weighed dye in distilled water to the required concentration for each of the experimental parameters been considered.

\section{Experiment procedures}

Effect of contact time on adsorption: The experiment on the effect of contact time on the adsorption of the dye ion by the cassava peel adsorbent was performed according to the previous works of Sumanjit et al. [11]. $2 \mathrm{~g}$ of the modified adsorbents was weighed into five different conical flasks. Concentration of $10 \mathrm{mg} / \mathrm{L}$ of the dye was prepared using distilled water and $50 \mathrm{~m} 1$ of the dye solution was measured into the five flasks. The flasks were then labeled for time intervals of 20, 40, 50, 60,80 and 100 minutes. The flasks were tightly covered and agitated at the appropriate time intervals. At the end of each time intervals, the suspensions were filtered using Whatman No. 45 filter paper and then centrifuged. The dye ion concentration was determined using DR 2010 spectrophotometer.

Effect of adsorbent dosage on adsorption: The experiment on the effect of adsorbent dosage on the adsorption of dye ion by the cassava peels adsorbent was performed according to the previous works of Sumanjit et al. [11]. 2, 3, 4, 5 and $6 \mathrm{~g}$ of the modified adsorbent were weighed into five different conical flasks. $50 \mathrm{ml}$ of the dye solution was measured into the five flasks. The flasks were then labeled for dosage differences of 2, 3, 4, 5 and $6 \mathrm{~g}$. The flasks were tightly covered and agitated for 20 minutes, thereafter the suspensions were filtered using Whatman No. 45 filter paper, then centrifuged. The dye ion concentration was determined using DR 2010 spectrophotometer.

Effect of dye ion concentration on adsorption: The experiment on the effect of dye ion concentration on adsorption was performed according to the previous works of Sumanjit et al. [11]. Several standard dye solutions of 10, 20,30, 40 and $50 \mathrm{mg} / \mathrm{L}$ were prepared. $50 \mathrm{ml}$ of each of the dye solution was added to accurately weighed $2 \pm 0.01 \mathrm{~g}$ modified adsorbent in five different flasks and agitated for 20 minutes. At the end of the time, the suspension was filtered using Whatman No. 45 filter paper and centrifuge. The dyes ion concentration was determined using Dr 2010 spectrophotometer.

Effect of temperature on adsorption: The experiment on the effect of temperature on adsorption was performed according to the previous work of Mishra et al. [12]. $2 \mathrm{~g}$ of the modified adsorbent was weighed into five different conical flasks and $50 \mathrm{~m} 1$ of the dye solution $(10 \mathrm{mg} / \mathrm{L})$ was measured into the five flasks. The flasks were labeled for temperature differences of $30,40,50,60$ and $70^{\circ} \mathrm{C}$. The flasks were tightly covered and heated at the appropriate temperature using thermostatic water bath, at 20 minutes each. At the end of the time, each of the flasks were brought out and agitated for about 5 minutes. After then, the suspensions were filtered using Whatman No. 45 filter paper and centrifuged. The dye ion concentration was determined using DR 2010 spectrophotometer.
Effect of $\mathbf{p H}$ on adsorption: The experiment on the effect of $\mathrm{pH}$ on adsorption was carried out based on the previous works of Sumanjit et al. [11]. Modified adsorbent $(2 \pm 0.0 \mathrm{lg})$ was weighed into five different flasks. $50 \mathrm{~m} 1$ of the dye solution $(10 \mathrm{mg} / \mathrm{L})$ was measured and added into the five flasks. The solutions were adjusted to $\mathrm{pH} 2.0,4.0,6.0,8.0$, and 10.0 by adding a solution of $\mathrm{HCl}(0.1 \mathrm{M})$ or $\mathrm{NaOH}(0.1 \mathrm{M})$ and the $\mathrm{pH}$ readings were confirmed by the use of $\mathrm{pH}$ meters. The flasks were then tightly covered and agitated for 20 minutes. At the end, the suspensions were filtered using Whatman No. 45 filter paper and centrifuged. The dye contents were determined using DR 2010 spectrophotometer.

\section{Data evaluation}

Calculation of the degree of dye removal: The amounts of dye removal by the adsorbent during the series of the batch experiments were determined using a mass balance equation expressed as shown below.

$$
q_{e}=\frac{V}{M}\left(C_{O}-C_{e}\right)
$$

Where $\mathrm{q}_{\mathrm{e}}$-dye concentration on the biomass $(\mathrm{mg} / \mathrm{g})$ at equilibrium $\mathrm{C}_{\mathrm{e}}=$ dye concentration in solution $(\mathrm{mg} / \mathrm{L})$ at equilibrium

$\mathrm{C}_{\mathrm{o}}=$ initial dye concentration in solution $(\mathrm{mg} / \mathrm{L})$

$\mathrm{V}=$ volume of dye solution used $(\mathrm{ml})$

$\mathrm{M}=$ mass of adsorbent used $(\mathrm{g})$

Kinetic treatment of experimental data: In order to comprehensively investigate the mechanism of adsorption, the equations of pseudo-first order and pseudo-second order mechanisms are applied to experimental data.

The linear form of pseudo-first-order model is given as:

$$
\ln \left(q_{e}-q_{t}\right)=\ln q_{e}-K t
$$

Where $\mathrm{q}_{\mathrm{e}}=$ mass of dye adsorbed at equilibrium $(\mathrm{mg} / \mathrm{g})$

$\mathrm{q}_{\mathrm{t}}=$ mass of dye adsorbed at time $\mathrm{t}(\mathrm{mg} / \mathrm{g})$

$\mathrm{K}=$ equilibrium constant

The linear plot of $\ln \left(\mathrm{q}_{\mathrm{e}}-\mathrm{q}_{\mathrm{t}}\right)$ versus $\mathrm{t}$ confirms the model. The linear form of pseudo-second-order model is given as:-

$$
\frac{t}{q_{t}}=\frac{1}{h_{o}}+\frac{t}{q_{e}}
$$

Where $\mathrm{q}_{\mathrm{t}}=$ amount of dye ions on the adsorbent surface $(\mathrm{mg} / \mathrm{g})$ at anytime t.

$\mathrm{q}_{\mathrm{e}}=$ the amount of dye ions adsorbed at equilibrium $(\mathrm{mg} / \mathrm{g})$

$\mathrm{h}_{\mathrm{o}}=$ the initial adsorption capacity $(\mathrm{mg} / \mathrm{g} \mathrm{min})$.

The initial adsorption rate $h_{o}$ is defined as:

$\mathrm{h}_{\mathrm{o}}=\mathrm{K}_{2} \mathrm{q}_{\mathrm{e}}^{2}$

Where $\mathrm{K}_{2}$ is the pseudo-second order rate constant ( $\mathrm{g} / \mathrm{mg} \mathrm{min}$ ).

\section{Results and Discussions}

\section{Effect of contact time on dye removal}

The effect of stay time for the adsorption of the dye was studied between the intervals of 20 minutes and was varied from 20 to 100 minutes. Figure 1 illustrates the adsorption of the dye at different time 


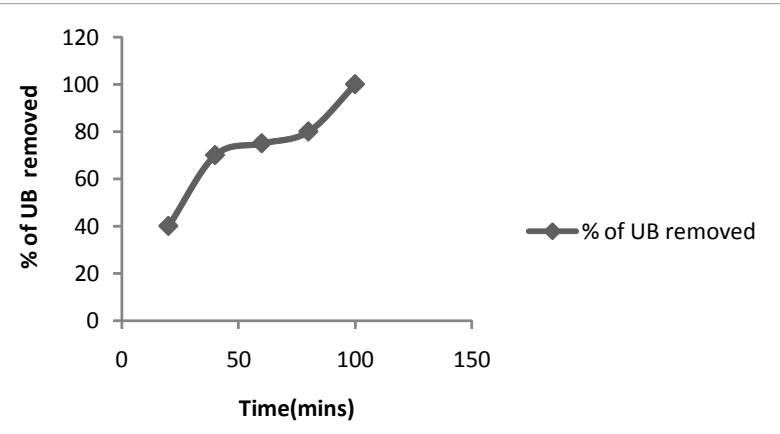

Figure 1: Effect of contact time on the adsorption of UB by cassava peels absorbent.

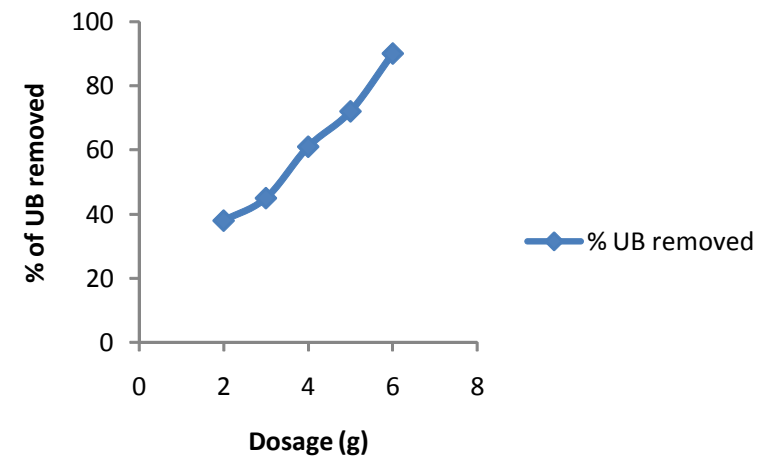

Figure 2: Effect of adsorbent dosage on the adsorption of UB

duration. As the contact time was increased from 20 to 100 minutes, the amount of dye removed increased from $0.105 \mathrm{mg} / \mathrm{g}$ to $0.245 \mathrm{mg} / \mathrm{g}$.

The figure also indicates that the amount of dye removed increased rapidly with increase in time, as well as the percentage of dye removed in which maximum percent (98\%) was obtained at 100 minutes. This may be due to the fact that as the dye solution-adsorbent system is being agitated at longer time, more of the molecules or atoms of the dye tend to accumulate on the surface of the adsorbate until equilibrium is reached.

However, similar trends have been observed by some other researchers [11-13].

\section{Effect of adsorbent dosage on dye removal}

The effect of the amount of adsorbent (cassava peels) on the adsorption of ultramarine blue system was studied, in which the amount of adsorbent was varied from 2 to $6 \mathrm{~g}$. Figure 2 shows the effect of adsorbent dosage on the removal of the dye in which the amount of dye removed increased from $0.095-0.228 \mathrm{mg} / \mathrm{g}$ as the adsorbent dosage was increased from 2-6 g.

From figure 2, it is observed that the optimized adsorbent dose is $6 \mathrm{~g}$ in which $0.228 \mathrm{mg} / \mathrm{g}$ of dye was adsorbed. More so, the maximum percentage $(91 \%)$ of dye adsorbed at this dosage $(6 \mathrm{~g})$ is also shown in figure 2. However, the increase in dye uptake could be attributed to certain reasons. According to Mishra et al. [12], the increase in dye uptake is obvious with increasing adsorbent dosage as the binding sites for adsorption increases. Meanwhile similar behavior has been reported by other workers $[11,14]$.

\section{Effect of concentration on dye removal}

The experimental results of the removal of ultramarine blue dye by cassava peels biomass at various initial dye concentrations are as shown in figure 3. The adsorption capacity increased from 0.185 to $1.027 \mathrm{mg} / \mathrm{g}$ with an increase in the concentration of dye from 10 to $50 \mathrm{mg} / \mathrm{L}$, having maximum adsorption of $1.027 \mathrm{mg} . \mathrm{g}$ at $50 \mathrm{mg} / \mathrm{L}$.

However, the actual percent removal of the dye was found to increase with increase in initial dye concentration as shown in figure 3. This may be due to the fact that as the dye concentration is increasing, more dye is available for adsorption on the absorbent. This is due to the effect of concentration gradient which is the main driving force for the adsorption process [12]. Similarly, this trend has been observed by other workers $[12,13]$.

\section{Effect of temperature on dye removal}

The dependence of dye adsorption on temperature was studied within the temperature range of $30-70^{\circ} \mathrm{C}$ at the intervals of $10^{\circ} \mathrm{C}$. The effect of temperature on the adsorption of dye is shown in figure 4, in which the amount of dye adsorbed increased from 0.115 to $0.123 \mathrm{mg} / \mathrm{g}$ with increases in temperature from 30 to $70^{\circ} \mathrm{C}$.

Though, the increase in the amount of dye removed as the temperature increases is not much significant, according to Hiroyuki et al. the higher removal due to increasing temperature may be attributed to chemical reaction taking place between the functional groups of the adsorbate/adsorbent [15]. Moreso, at high temperature, there is increase in the mobility of the large dye ion thereby producing swelling effect within the internal structure of the adsorbent, thus enabling the large dye molecule to penetrate further [16].

Despite the afore-mentioned reasons accompanying increased adsorption with increased temperature, it has been reported, that increase in adsorption at higher temperature is difficult to explain.

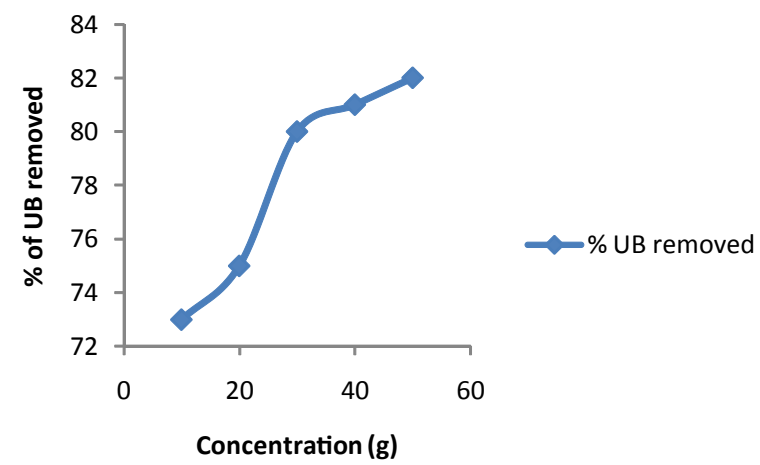

Figure 3: Effect of concentration on dye removal.



Figure 4: Effect of temperature on UB removal. 
However, the trend of increased adsorption with increased temperature has been reported by other workers [13,17].

\section{Effect of $\mathrm{pH}$ on dye removal}

The $\mathrm{pH}$ of an aqueous medium is an important factor that may affect the uptake of the adsorbate. The chemical characteristics of both adsorbate and adsorbent vary with $\mathrm{pH}$. According to Horsfall et al. most plant materials are made up of complex organic residues such as lignin and cellulose that contain, several type of polar functional groups [18]. These groups can be involved in chemical bonding and may be responsible for the typical cation-exchange characteristics of most biomaterials.

The $\mathrm{pH}$ dependence data for adsorption of the dye being investigated are presented in figure 5. It is observed that as the $\mathrm{pH}$ of dye solution increased from 2-8, the amount of dye adsorbed decreased from 0.135 to $0.087 \mathrm{mg} / \mathrm{g}$, though at $\mathrm{pH} 10$ there was a rapid increase in the amount of dye adsorbed. The initial decrease in the amount of dye adsorbed as the $\mathrm{pH}$ increases may be due to the fact that ultramarine blue exists in anionic form at basic $\mathrm{pH}$ and in cationic form at acidic $\mathrm{pH}$.

However, according to Yamin et al. [14], in the study of removal of methylene blue by treated activated carbon, in which removal of methylene blue increased with the increased $\mathrm{pH}$; lower adsorption of methylene blue at low $\mathrm{pH}$ is probably due to the presence of hydrogen ions, competing with the cation groups on the dye for adsorption sites. So on the contrary, the initial higher adsorption of ultramarine blue at low PH may be probably due to the absence of hydrogen ions which cannot complete with the cation groups on the dye for adsorption. Meanwhile similar trend has been reported in the literature for the adsorption of Congo red dye onto Mahua oil cake [12].

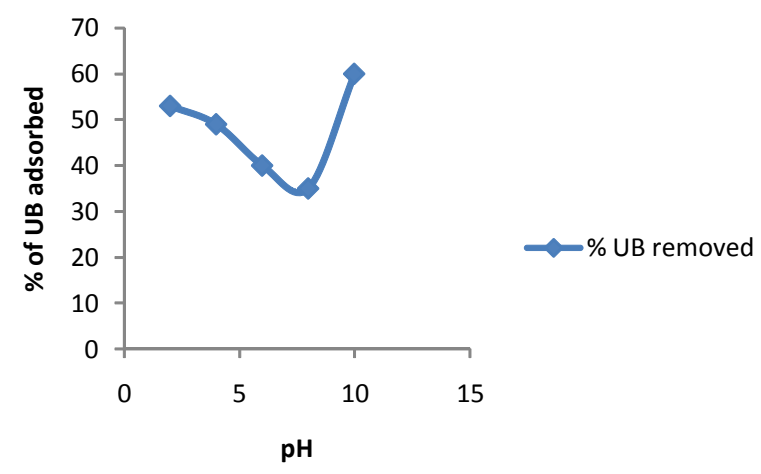

Figure 5: Effect of $\mathrm{PH}$ on dye removal.

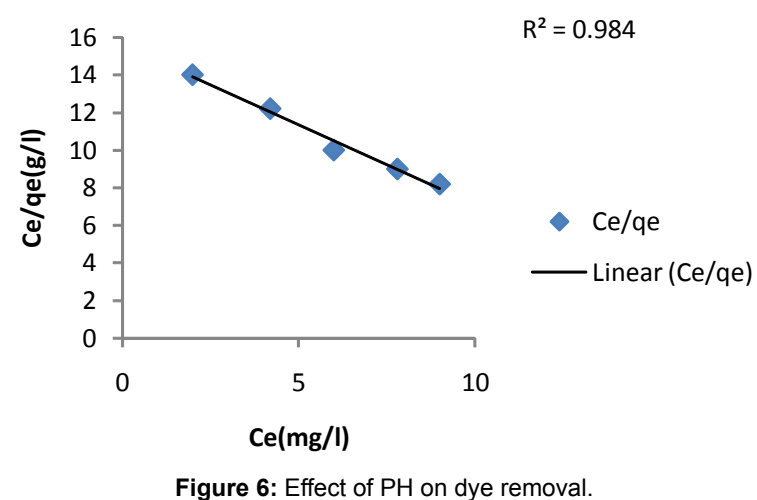

Figure 6: Effect of $\mathrm{PH}$ on dye removal.

\section{Isotherm evaluation}

Langmuir isotherm: The Langmuir isotherm model was chosen for the estimation of maximum adsorption capacity corresponding to complete monolayer coverage on the biomass surface. The plot of specific adsorption $\left(\mathrm{C}_{\mathrm{e}} / \mathrm{q}_{\mathrm{e}}\right)$ against the equilibrium concentration $\left(\mathrm{C}_{\mathrm{e}}\right)$ is shown in figure 6 and the linear isotherm parameters, $\mathrm{q}_{\mathrm{m}}, \mathrm{k}_{\mathrm{L}}$ and the coefficient of determinations are presented in figure 6 .

The $\mathrm{R}^{2}$ value suggested that the Langmuir isotherm provides a good model of the adsorption. The favorability of adsorption of the dyes ions on the cassava peels waste biomass was tested using the essential features of the Langmuir isotherm model, expressed in terms of a dimensionless constant called separation factor, $S_{F}$ proposed by Putshaka et al [19]. The separation factor $S_{\mathrm{F}}$ is defined by the following relationship.

$$
S_{F}=\frac{1}{1+K_{L} C_{O}}
$$

Where $\mathrm{K}_{\mathrm{L}}=$ Langmuir isotherm constant $\mathrm{C}_{\mathrm{o}}=$ initial dye ion concentration of $10 \mathrm{mg} / \mathrm{L}$. The parameter indicates the shape of the isotherm as follows:

$$
\begin{aligned}
& \mathrm{S}_{\mathrm{F}}>1 \text { unfavourable isotherm } \\
& \mathrm{S}_{\mathrm{F}}=1 \text { linear isotherm } \\
& \mathrm{S}_{\mathrm{F}}=0 \text { irreversible isotherm } \\
& 0<\mathrm{S}_{\mathrm{F}}<1 \text { favourable isotherm }
\end{aligned}
$$

The separation parameters for the dye is less than unity indicating that cassava peel waste biomass is an excellent adsorbent for ultramarine blue ions. The separation parameter and other Langmuir isotherm parameters are shown in table 1.

Freundlich isotherm: The Freundlich model was chosen to estimate the adsorption intensity of the adsorbate on the adsorbent surface. The linear Freundlich isotherms for the adsorption of the dye ion onto cassava peel waste biomass are presented in figure 7 . Examination of the plot reveals that the Freundlich isotherm is also an appropriate model for the adsorption process under consideration. Table 2 shows the linear Freundlich sorption isotherm parameters and the coefficient of determination $\left(\mathrm{R}^{2}\right)$.

Based on the value of $\mathrm{R}^{2}$, the linear plot form of the Freundlich isotherm appears to produce a reasonable model for the adsorption process under consideration.

\section{Adsorption kinetics}

First order plot: The kinetic of adsorption is probably the most

\begin{tabular}{|c|c|c|c|c|}
\hline Dye in & $1 / n$ & \multicolumn{2}{|l|}{$\mathrm{K}_{\mathrm{F}}$} & $\mathrm{R}^{2}$ \\
\hline UB & 1.978 & \multicolumn{2}{|l|}{0.045} & 0.985 \\
\hline \multicolumn{5}{|c|}{ Table 2: Freundlich isotherm constant. } \\
\hline \multirow[t]{2}{*}{ Dye ion } & Ho & $\mathrm{K}^{2}$ & $q_{e}$ & $R^{2}$ \\
\hline & $\left(\mathrm{mgg}^{-1} \mathrm{~min}^{-1}\right)$ & $\left(\mathrm{mgg}^{-1} \mathrm{~min}^{-1}\right)$ & $\left(\mathrm{mgg}^{-1}\right)$ & \\
\hline U.B & 0.008 & 0.072 & 0.333 & 0.956 \\
\hline
\end{tabular}
important factor in predicting the rate at which adsorption takes place for a given system.

\begin{tabular}{|l|l|l|l|l|}
\hline Dye ion & $\mathrm{q}_{\mathrm{m}}(\mathrm{mg} / \mathrm{g})$ & $\mathrm{K}_{\mathrm{L}}\left(\mathrm{L}_{\mathrm{g}}{ }^{-1}\right)$ & $\mathrm{R}^{2}$ & $\mathrm{~S}_{\mathrm{F}}$ \\
\hline UB & 0.952 & 0.058 & 0.984 & 0.633 \\
\hline
\end{tabular}

Table 1: Linear langmuir isotherm parameters.

Table 3: Values of pseudo-second order kinetic parameters. 


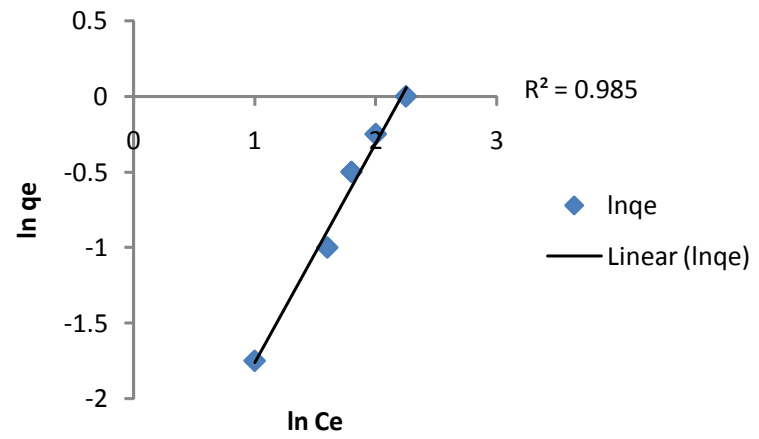

Figure 7: Freundlich equilibrium isotherm model for dye removal.



Figure 8: Pseudo - first order plot.

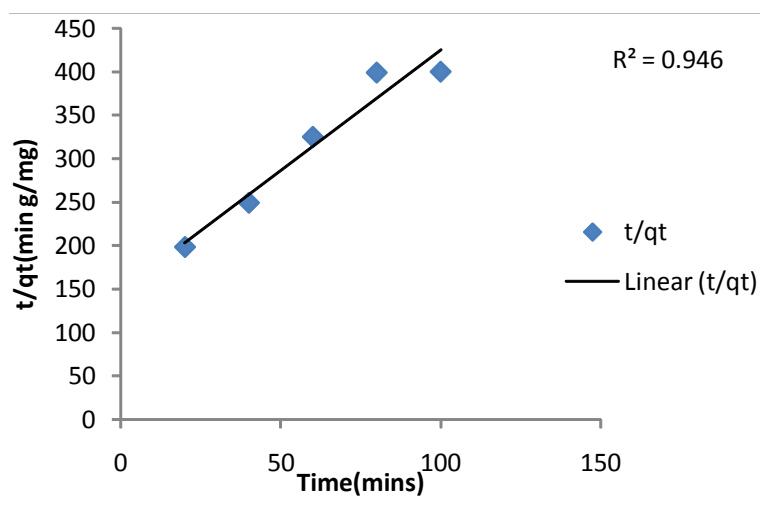

Figure 9: Pseudo - second order plot.

A plot of $\operatorname{In}\left(\mathrm{q}_{\mathrm{e}}-\mathrm{q}_{\mathrm{t}}\right)$ against $\mathrm{t}$ as shown in figure 8 gave the pseudofirst order kinetics. From the plot, it is observed that the relationship between dye ion diffusivity, $\operatorname{In}\left(\mathrm{q}_{\mathrm{e}}-\mathrm{q}_{\mathrm{t}}\right)$ and time $(\mathrm{t})$ is linear which confirms the model. The value of the coefficient of determination $\mathrm{R}^{2}$ as shown in table 2 indicates that pseudo-first order model provided a good description for the adsorption of ultramarine blue on the cassava peels biomass.

However in confirming the linearity of the pseudo-first order model, the same observation has been reported by Gunusamy for the adsorption of basic dye on strongly chelating polymer [17].

Pseudo-second order model: A plot of $t$ /qt against $t$ as shown in figure 9 gave the pseudo-second order kinetics. From the plot, it is observed that the relationship between $t / q t$ and $t$ is linear which confirms the model. Also, the initial sorption rate ho, the equilibrium adsorption capacity $\mathrm{q}_{\mathrm{e}}$, the pseudo-second order rate constant $\mathrm{K}_{2}$ and the coefficient of determination $\mathrm{R}^{2}$ are presented in table 3 .
Based on the value of the coefficient of determination $\mathrm{R}^{2}$, the pseudosecond order model provides a better description for the adsorption process better than pseudo-first order model. This observation has been reported by Che for the adsorption of basic blue, acid blue and direct red dyes using clay-based activated carbon adsorbent [20].

\section{Thermodynamic parameters}

The values of the thermodynamic parameters like free energy $\left(\Delta^{\circ} \mathrm{G}\right)$, enthalpy $\left(\Delta^{\circ} \mathrm{H}\right)$ and entropy $\left(\Delta^{\circ} \mathrm{S}\right)$ of the adsorption process were calculated from the Langmuir constant $\mathrm{K}$ using the following equations.

\section{$\Delta \mathrm{G}=-\mathrm{RT}$ Ink}

Ink $=\Delta S-\Delta \mathrm{H}$

\section{R RT}

$$
\Delta \mathrm{G}=\Delta \mathrm{H}-\mathrm{T} \Delta \mathrm{S} \text {. }
$$

The value of $\Delta \mathrm{H}^{\circ}$ and $\Delta \mathrm{S}^{\circ}$ were calculated from the slope and intercept of the linear variation of lnk with the reciprocal of temperature $(1 / \mathrm{T})$ and are given in figure 10.

The calculated values of $\Delta \mathrm{G}^{\circ}$ at different temperatures are positive, showing that the adsorption process is not spontaneous. The values of enthalpy are also positive, which reveals the endothermic nature of the process the values of entropy are negative. Meanwhile, the same observation has been reported as regards the endothermic nature of the process by Hajira et al. for the removal of basic dye methylene blue by using bioadsorbents ulva lactuca and sargassum [13].

\section{Conclusions}

Modified cassava peels biomass has been studied and found to be an excellent absorbent for ultramarine blue (UB) removal. Increasing the dye ion (UB) concentration led to increase in percentage removal of the dye ions. Also, increase in absorbent dosage led to a very significant increase in percentage UB removal. Adsorption of the dye ions was found to increase with increases in contact time. $\mathrm{pH}$ of 10 was found to be the critical $\mathrm{pH}$ for UB adsorption on the modified cassava peels biomass. The equilibrium data fit well into the Langmuir and Freundlich isotherm models. The separation factor obtained from the Langmuir isotherm showed that the adsorption of the dye ions onto the cassava peels biomass was favorable. Pseudo second order model was found to be a better descriptor of the UB adsorption. The investigated thermodynamic parameters showed that the adsorption process was endothermic and non-spontaneous. Given the above findings, modified cassava peels can be used as an alternative to the expensive conventional methods of dye removal from wastewater. It is therefore



Figure 10: Thermodynamic Plot. 
Citation: Owamah HI, Izinyon OC, Asiagwu AK (2012) Sorption Model and Kinetic Assessment of Ultramarine Blue Removal using Modified Cassava Peels Biomass. J Civil Environ Eng 2:122. doi:10.4172/2165-784X.1000122

recommended for small and medium scale industries, whose financial status may not conveniently afford the treatment of their wastewater, using conventional methods. Again, cassava peels which are ordinarily an environmental nuisance, when used for wastewater treatment, would have served as a means for recycling it and thereby reducing its attendant public health concerns.

\section{References}

1. Jambulingam M, Karthikeyan S, Sivakumar $P$, Kiruthika J, Maiyalagan T (2007) Characteristic studies of some activated carbons from agricultural wastes. J Sci Ind Res 66: 495-500.

2. Karthikeyan S, Sivakumar P, Palanisamy PN (2008) Novel activated carbons from agricultural wastes and their characterization. E J Chem 5: 409-426.

3. Lua AC, Guo J (1998) Preparation and characterization of chars from oil palm waste. Carbon 36: 1663-1670.

4. Sujatha M, Geetha A, Sivakumar P, Palanisamy PN (2008) Orthophosphoric Acid Activated Babul Seed Carbon as an Adsorbent for the Removal of Methylene Blue. E J Chem 5: 742-753.

5. Sarin V, Singh TS, Pant KK (2006) Thermodynamic and Breakthrough Column Studies for the Selective Sorption of Chromium from Industrial Effluent on Activated Eucalyptus Bark. Bioresource Technol 97: 1986-1993.

6. Özacara M, Sengil SI (2005) Adsorption of metal complex dyes from aqueous solutions by pine sawdust. Bioresource Technol 96: 791-795.

7. Wu FC, Tseng RL, Hu CC (2005) Micropor. Mesopor. Mater: 80-95.

8. Sivakumar $P$, Palanisamy N (2010) Mechanistic study of dye adsorption onto a novel non-conventional low-cost adsorpbent. Adv App Sci Res 1: 58-65.

9. Grag VK, Kumar R, Gupta R (2004) Removal of malachite green dye from aqueous solution by adsorption using agro-industries waste: a case study of phosopis cineraria. Dyes Pigments 62: 1-10.
10. McKay G, Otterburn MS, Sweeney AG (1980) Kinectics of colour remova from effluent using activated carbon. J Soc Dyers Colourists 96: 576-579.

11. Sumanjit W, Walia TPS, Ravneet K (2007) Removal of Health Hazards Causing Acidic Dyes from Aqueous Solutions by the Process of Adsorption. OJHAS 6 : $1-10$.

12. Mishra S, Prakash D J, Ramakrishma G (2009) Characterization and Utilization of Mahua Oil Cake-A New Adsorbent for Removal of Congo Red Dye from Aqueous phase. Electronic Journal of Environmental, Agricultural and Food Chemistry 6: 425-436.

13. Tahir H, Sultan M, Jahanzeb Q (2008) Removal of Basic Dye Methylene Blue by using Bioabsorbent Ulva Lactuca and Sargassum. Afr J Biotechol 7 2649- 2655.

14. Yamin Y, Mold ZH, Faujan HA (2007) Adsorption of Methylene Blue onto created activated carbon. Malaysian Journal of Analytical Science 11: 400-406.

15. Hiroyuki H, Okomoto A, Kataoka T (1994) Adsorption of Acid Dye Cross-linked Chitosan Fibres Equilibria. Chemical Engineering Science 12: 2267-2272.

16. McKay G (1982) Adsorption of dyestuffs from aqueous solutions with activated carbon 1: Equilibrium and batch contact-time studies. J Chem Technol Biotechnol 32: 759-772.

17. Gunmany A (2002) Adsorption of Basic Dye on Strongly Chelating Polymer Batch Kinetic Studies . Iramian Polymer Journal 11: 237-244.

18. Horsfall, Jnr M, Abia AA, Spiff Al (2003) Removal of $\mathrm{Cu}(\mathrm{II})$ and $\mathrm{Zn}(\mathrm{II})$ lons from Wastewater by Cassava (Marrihot Escalenta Cranz) Waste Biomass. Afr J Biotechnol 10: 360-364

19. Putshaka JD, Harami A, Zakari L (2005) Synthesis of Azo Dyes from the Husk of Paraika Clappertomicina. Journal of Raw Materials Research 2: 39-44.

20. Ani YBC (2004) Adsorption Studies of Dyes using Clay-based and Activated Carbon Adsorbent. Malaysian Journal of Analytical Sciences 1: 17-24 